\title{
ESTADOS TRANSITORIOS DE HUMOR DE ATLETAS DE BASQUETE
}

Anderson Wagner dos Santos

Daniel Simões Rebello

Danielle Bernardes-Amorim

\section{Resumo}

O objetivo deste estudo foi analisar os estados transitórios de humor de atletas de basquete participantes dos jogos do JIMI (Jogos do Interior de Minas). Para sua realização, foram selecionados 10 adultos da faixa etária entre 18 a 27 anos, do sexo masculino, participantes da fase classificatória do JIMI de basquete masculino que ocorreu no mês de junho deste ano. Para coleta dos dados, foi aplicado o questionário POMS (perfil dos estados de humor) que contem 65 itens que abordam o vigor como fator positivo de humor, e como fatores negativos, tensão, raiva, fadiga, depressão e confusão mental. Os dados do teste de POMS foram anotados em planilhas especificando os avaliados, jogo (primeiro e segundo) e momento (pré e pós) e foram calculadas as medias de cada estado em cada um dos momentos de cada jogo. Em seguida, foi feita a análise de variância e pós-teste de comparação. Como resultado, verificou-se que os atletas tiveram seus estados de humor (fadiga, raiva, depressão, vigor) muito altos durante os dois jogos, sendo que tensão e confusão mental não se alteraram. Porém, entende-se como necessário a realização de outros estudos sobre as emoções e sentimentos dos jogadores de basquete, para que de algum modo possamos auxiliar em futuros campeonatos.

\section{Palavras-Chave}

Basquete; Psicologia; Humor.

\section{TRANSITORY STATES OF BASKETBALL ATHLETES' HUMOR}

Anderson Wagner dos Santos

Daniel Simões Rebello

Danielle Bernardes-Amorim

\begin{abstract}
The objective of this study was to analyze the transitory states of athletes humor of basket in games GIMI (Games of Minas Interior). For this achievement, were selected 10 adults between 18 to 27 years old, male, participants of classificatory state JIMI that occurred in month June this year. For the collection's affable, was applied questionnaire POMS (Profile's humor states) that contain 65 articles that accost the vigor as positive factor of humor, and as negatives factors, tension, anger, toil, depression and mental confusion. The grades of the POMS test were noticed in plans, specifying the ones that are evaluated, the game's moment and game (first and second) and moment (pre and pos) and were calculated the average of each state and moments of each game. Next, the analysis and pos-test comparison. As a result, verified that athletes had yours humor states (toil, anger, depression, vigor) many high during both games, being that tension and mental confusion don't alter. However, we understand that is necessary the realization of others studies about emotions and basket player's feeling, for this we can help in future championship.
\end{abstract}

\section{Key-Words:}

Basket; Psychology; Humor. 


\section{INTRODUÇÃO}

Quando James Naismit, em 1890, criou o basquete como um esporte coletivo no qual duas equipes têm que fazer o maior número de cestas uma contra outra, provavelmente não tenha imaginado que o basquete seria um esporte de nível tão alto onde só preparo físico não é mais sinônimo de vitórias (FERREIRA, 1987).

No esporte de alto nível, a busca pelo rendimento máximo é constante assim como é o objetivo principal dos programas de treinamento elaborados pelos técnicos. Porém, quando este objetivo não é alcançado, o efeito emocional da derrota é difícil de ser superado e a tensão do atleta devido à cobrança do técnico e dos espectadores torna-se um sentimento de medo, uma vez que não se pode garantir com esse ou com aquele tipo de treinamento o atleta terá a performance esperada, chegando a vitória e debatendo-se contra a derrota (CRATTY, 1984).

Neste sentido, a prática de esportes coletivos, faz com que o atleta tenha que ter a habilidade de deslocar-se entre diferentes categorias de controle de estímulos e humor, ou seja, o atleta tem que ter a habilidade de deslocar sua atenção de um tipo de estímulo para outro (RUBIO, 2.000).

Segundo Samulski (2002), em uma competição, o esportista se encontra em um estado de estresse psíquico, que para alguns autores tem sido denominado estado pré-competitivo. Esse estado se caracteriza, sobre o ponto de vista psicológico, pela antecipação das oportunidades, riscos e conseqüências. Nesta fase intervém frequentemente medo e temor. Esses estados se manifestam em preocupações, mas também podem produzir reações motoras e emocionais.

Os estados pré-competitivos são limitados, dinâmicos e temporários e os seguintes fatores têm uma grande influencia na qualidade e intensidade dos estados pré-competitivos: a importância subjetiva da competição e das conseqüências correspondentes, a relação atleta-técnico, o nível de rendimento do adversário e as experiências competitivas em nível de alta confiança. Assim, o fato de um atleta estar psiquicamente mal preparado pode resultar em um estado emocional negativo antes da competição (BROTTO, 2001).

Segundo Almeida (2000) o treinador deve ser acima de tudo, um educador, um formador de pessoas. Sempre pensar que antes do atleta existe o ser humano. Não se sabe se ele vai seguir em uma modalidade ou vai mudar de esporte.

Samulski (2002) também diz que atletas de esportes coletivos deveriam ter o apoio de seu treinador, porque o treinador irá preparar taticamente o esportista, motivará durante a competição, tranqüilizara quando estiver 
nervoso e fará um clima emocional positivo durante o treino e competição. Todas estas técnicas de controle emocional devem ser aplicadas de forma preventiva ou compensatória (técnicas de prevenção e compensação), e podem combinar e variar a diferentes técnicas de controle, considerando as necessidades individuais do atleta, a estrutura da tarefa a complexidade e importância da situação.

\section{OBJETIVO}

O presente estudo teve como objetivo, através do teste de POMS (Profile of Mood States), um instrumento de avaliação dos estados transitórios de humor desenvolvido por MCNAIR, LOOR E DROPPLEMAN em 1971, citado por SILVA, 2006, avaliar as características da personalidade de jogadores de basquete da cidade de Pouso Alegre (MG) e suas variáveis de humor, que aborda o vigor como fator positivo e, como fatores negativos: tensão, raiva, fadiga, depressão e confusão mental, durante o JIMI (Jogos do Interior de Minas).

\section{METODOLOGIA}

\section{POPULAÇÃO DO ESTUDO E SELEÇÃO DA AMOSTRA}

Para a realização deste estudo, foram convidados os adultos da faixa etária entre 18 e 27 anos, do sexo masculino freqüentadores das aulas de basquete do poli esportivo municipal, localizado na cidade de Pouso Alegre (MG).

Após o contato inicial com o poli esportivo mencionado, quando foi feito o pedido formal de consentimento para a realização do estudo, os freqüentadores foram abordados durante as aulas em dias e horários diferentes e receberam o Termo de Consentimento e autorizaram formalmente sua participação no estudo.

Após esta autorização, cientes de estarem participando voluntariamente e de não haver nenhuma conseqüência pela não participação, os freqüentadores foram informados de que como seria a dinâmica de aplicação do questionário durante os Jogos do Interior de Minas (JIMI) e de que somente os participantes de tal campeonato seriam sujeitos do referido estudo. Assim, foram selecionados 10 atletas masculinos participantes da fase classificatória do campeonato JIMI de basquete masculino que ocorreu no mês de junho deste ano.

\section{INSTRUMENTO E PROCEDIMENTO PARA COLETA DOS DADOS}

Para coleta dos dados, foi aplicado um instrumento conhecido e validado para avaliar o humor dos atletas antes e após cada partida de basquete em que os selecionados no poli esportivo municipal de Pouso Alegre (MG) participassem. 
Este instrumento foi o POMS (Profile of Mood States), um questionário que contem 65 itens para avaliar vigor como fator positivo de humor, e como fatores negativos, tensão, raiva, fadiga, depressão e confusão mental.

Inicialmente foi perguntado aos atletas "Como se sente?" e eles deveriam responder sinceramente (conforme solicitado) de acordo com o critério de cinco alternativas que significavam: 0 (nada), 1 (um pouco), 2 (mais ou menos), 3 (bastante), 4 (extremamente) para cada item do questionário.

\section{ANÁLISE DE DADOS}

Os dados do teste de POMS foram anotados em planilhas especificando os avaliados (dez no total), o jogo (primeiro ou segundo) e o momento (pré ou pós) e analisados para cálculos dos estados de humor (tensão, depressão, raiva, vigor, fadiga e confusão mental). Depois foram calculados as médias e desvios padrão de cada estado em cada um dos momentos de cada jogo. Em seguida, foi feita a análise de variância e pós-teste de comparação de Tukey.

\section{RESULTADOS}

O JIMI (Jogos do Interior de Minas) caracteriza-se por ser o maior evento de esportes de Minas, sendo dividido em três etapas: microrregionais, regionais e etapa final. Em se tratando do basquete da cidade de Pouso Alegre, foi disputada a primeira etapa (microrregional) que ocorreu em disputa de 12 microrregiões (com cerca de 3 cidades em cada uma delas), sendo que classificaria em cada chave duas equipes para a segunda etapa. Assim, o estudo do POMS com os jogadores de basquete de Pouso Alegre foi feito antes e pós os dois jogos da primeira etapa do JIMI.

O nível de tensão começou alto antes do primeiro jogo, sofreu uma ligeira diminuição após o final do mesmo, teve um leve antes do segundo jogo e mais um ligeiro aumento após o segundo jogo. Porém, como o valor de P é 0,1538 , este resultado foi considerado não significante. 


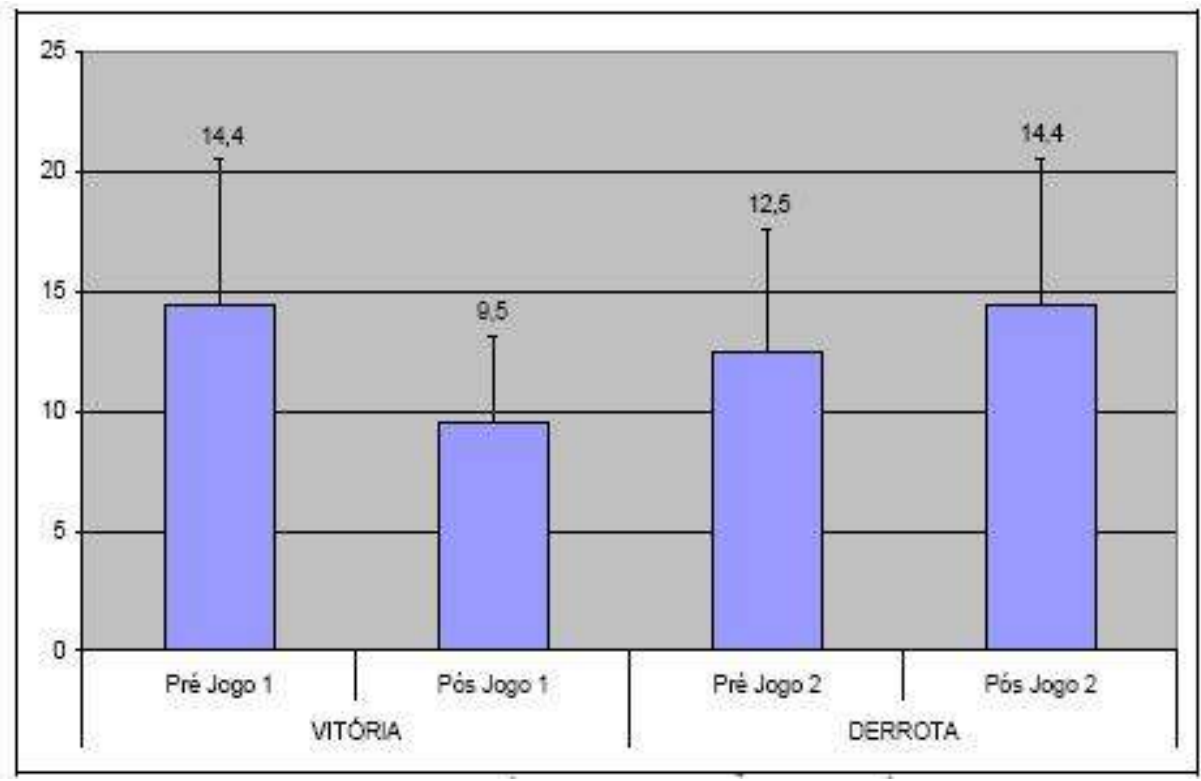

Figura 1 - Resultados do estado transitório de humor TENSÃO antes e após dois jogos de basquete

As emoções são responsáveis por alterações tanto fisiológicas quanto psicológicas durante a prática de esportes em um indivíduo. Sobre o assunto Lawther (1973 citando ARNOLD, 1945) ressalta que quando os impulsos, incentivos, motivos ou estímulos externos do homem se tornam tão fortes a ponto de causar reação parassimpática, causando uma afobação, mais energia e poderosos sentimentos de agitação. Esses sentimentos e alterações fisiológicas recebem vários nomes como, estado de tensão, excitação ou agitação emocional. Apesar de não significativo, percebe-se que antes do primeiro jogo os atletas encontravam-se neste estado de maior tensão, provavelmente pela situação desconhecida do que seria o campeonato.

Já o nível de depressão começou baixo, sofreu um aumento elevado após o primeiro jogo, começou baixo no segundo jogo e se manteve após o mesmo. Como o valor de $\mathrm{P}$ foi $<0,0001$, entre Pós jogo 1 e Pré jogo 1; Pós jogo 1 e Pré jogo 2; Pós jogo 1 e Pós jogo 2 este resultado é considerado extremamente significante. 


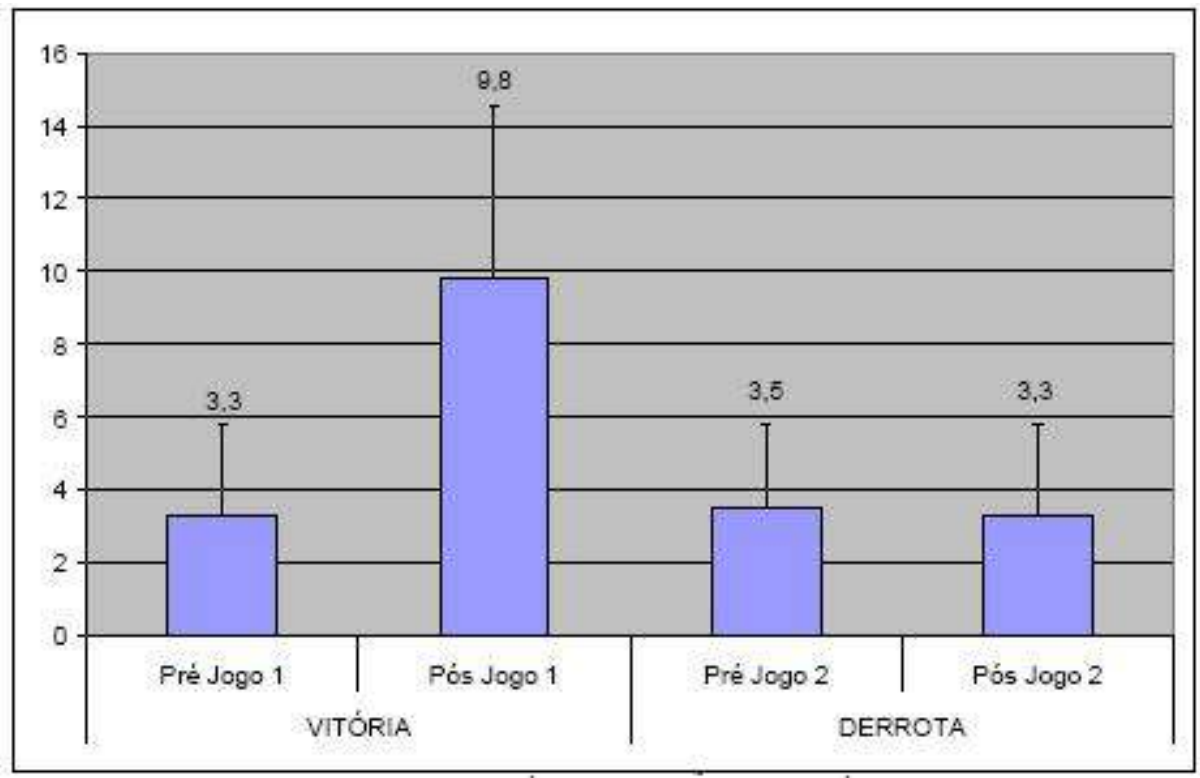

Figura 2 - Resultado do estado transitório DEPRESSÃO antes e após dois jogos de basquete.

Percebe-se que mesmo tendo obtido vitória no primeiro jogo o momento logo após este foi o de maior depressão. Talvez este fato possa ser explicado pela insatisfação com o desempenho no primeiro jogo.

Mas Samulski (2002) enfatiza que depressão e ansiedade em excesso interferem negativamente no desempenho de atletas, essas emoções aumentam a adrenalina, que pode fazer com que o atleta se apresse em executar ações que requerem atenção e cuidado. E, talvez este sentimento no primeiro jogo possa ter culminado na derrota do segundo jogo.

Com relação ao nível de raiva, verifica-se na Figura 3 que este começou baixo, teve um ligeiro aumento após o primeiro jogo, uma pequena diminuição no inicio do segundo jogo e continuou a diminuir após o segundo jogo. Como o valor de P foi < 0,0001, entre Pós jogo 1 e Pré jogo 1; Pós jogo 1 e Pré jogo 2; Pós jogo 1 e Pós jogo 2 este resultado é considerado extremamente significante. 


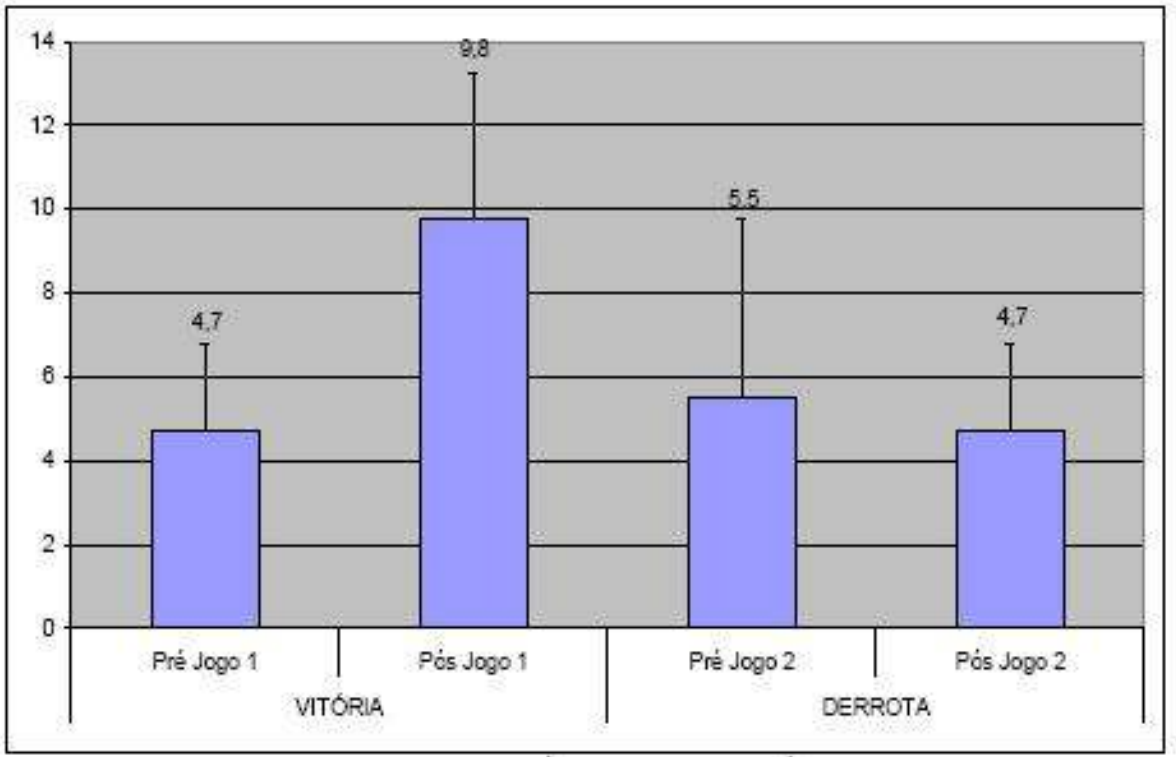

FIGURA 3 - Resultado do estado transitório RAIVA antes e após dois jogos de basquete.

Esta figura apresenta-se de forma semelhante ao ocorrido com o sentimento depressão (figura 2). Após o primeiro jogo, apesar da vitória, o sentimento de raiva foi o maior encontrado o que pode significar mais uma vez o descontentamento com o desempenho na partida. Logicamente, se tratando de uma competição, para alcançar uma meta desejada, se requer um determinado gasto psicológico, que se demonstram quando suas próprias capacidades são postas à prova diante de um desafio.

Quanto a isto, Samulski (2002) coloca que a raiva se manifesta quando se tem uma meta que foi perdida por não ter havido esforço suficiente, ou se não puder ser alcançada mesmo com muito esforço. Pode se dizer que a origem da raiva tem por base o fracasso e o não cumprimento das expectativas, que se supunham segura, mas que não foram concretizadas.

Já Biaggio (1996) diz que existem quatro escalas para a raiva: raiva para fora em que sua tendência é agredir os outros ou o ambiente; raiva para dentro que possui tendência inconsciente e culpa a si próprio, podendo levar à depressão; controle da raiva que pode levar supressão da mesma e; expressão que é utilizada para se medir o nível de raiva, levando em conta as três escalas anteriores.

Provavelmente, estes atletas experimentaram a raiva para dentro o que também pode ter prejudicado o resultado do segundo. 
E este fato também pode explicado pelo ocorrido na próxima figura que demonstra o nível de vigor. Este começou alto no inicio do primeiro jogo, sofreu grande diminuição após o mesmo, voltou a aumentar no segundo jogo continuou o aumento após o mesmo. Como o valor de $\mathrm{P}$ foi $<0,0001$, entre Pré jogo 1 e Pós jogo 1; Pós jogo 1 e Pré jogo 2; Pós jogo 1 e Pós jogo 2 este resultado é considerado extremamente significante.

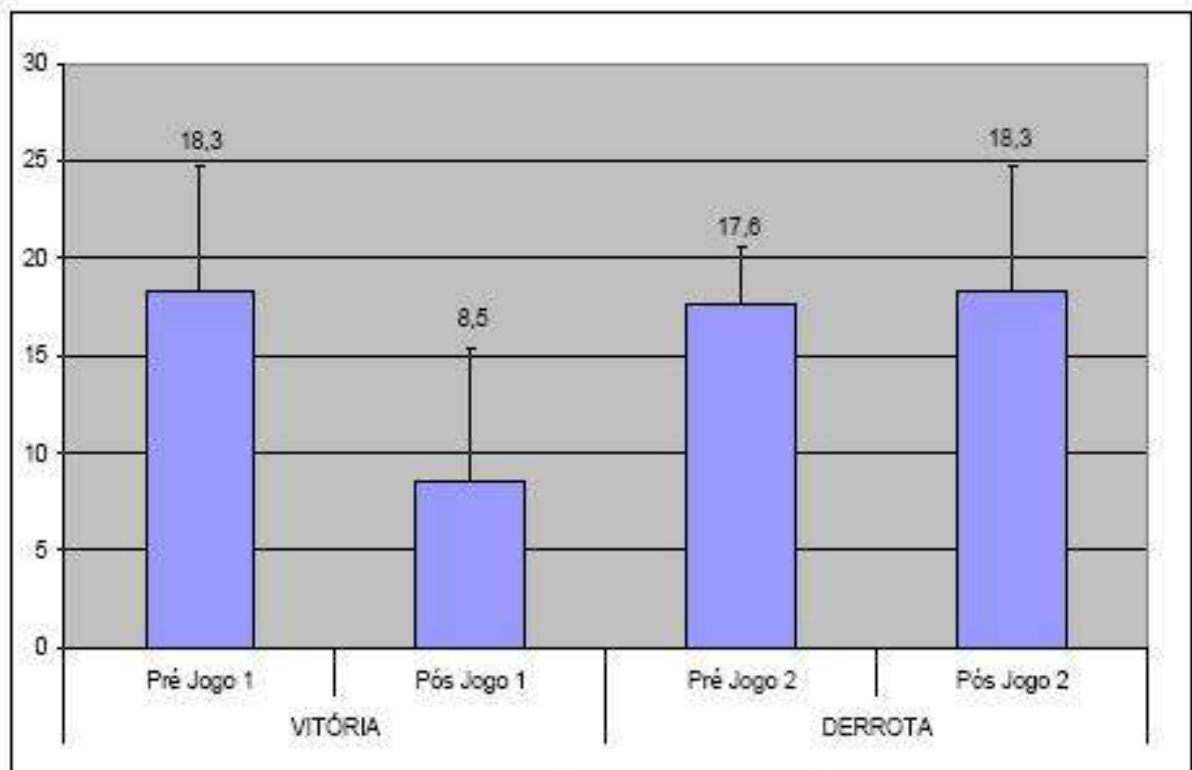

Figura 4 - Resultado do estado transitório VIGOR antes e após dois jogos de basquete.

Segundo Monti (2006), diante de situações de competição o desempenho físico acaba fazendo coisas extraordinárias, que normalmente não seriamos capazes de fazer em situações não competitivas, mas que isto é até certo ponto, até que nosso organismo atinja um máximo de eficiência. Então, o vigor se esvai. Este fato pode ter ocorrido com os atletas de basquete após sentirem que sua performance, por mais que rendido vitória, não tenha sido o esperado.

Aliás, este fato também pode ser demonstrado na figura $5 \mathrm{em}$ que se verifica que o nível de fadiga começou baixo no inicio do primeiro jogo e teve um grande aumento após este jogo. E, o mais importante já começou alto no segundo jogo, diminuindo logo após. Como o valor de $\mathrm{P}$ foi $<0,0001$, entre Pré jogo 1 e Pós jogo 1; Pré jogo 1 e Pré jogo 2; Pós jogo 1 e Pós jogo 2; Pré jogo 2 e Pós jogo 2 o resultado é considerado extremamente significante. Ou seja, os jogadores que já chegaram cansados para a segunda partida. 


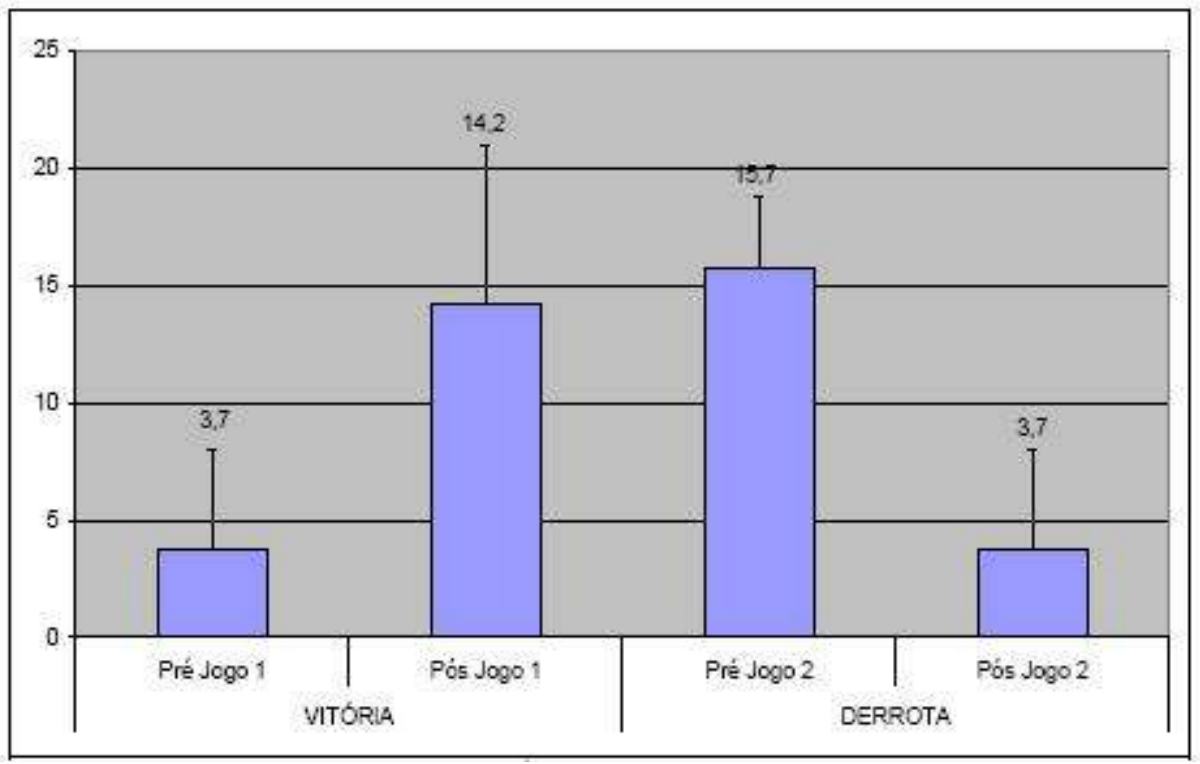

Figura 5 - Resultado do estado transitório FADIGA antes e depois de dois jogos de Basquete

Finalmente o nível de confusão mental começo um pouco alto, aumentou ligeiramente, teve uma pequena diminuição no segundo jogo e se manteve como no início do primeiro jogo. Porém, como o valor de P. é 0,3526 , este resultado foi considerado não significante.

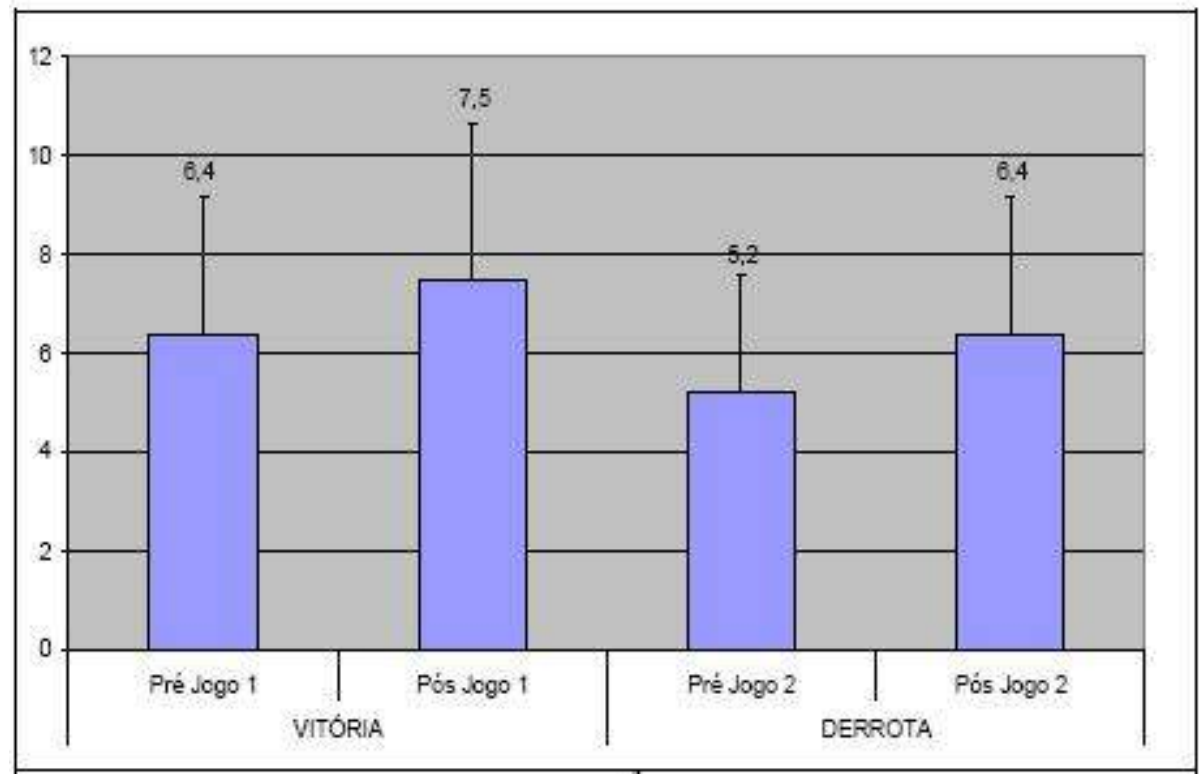

Figura 6 - Resultado do estado transitório CONFUSÃO MENTAL antes e após dois jogos de basquete. 


\section{CONCLUSÕES}

Com este trabalho pode-se observar que os atletas de basquete do poliesportivo municipal de Pouso Alegre (MG) que participaram dos Jogos do Interior de Minas (JIMI), tiveram os estados transitórios de humor depressão, raiva, vigor e fadiga muito alterados durante os dois jogos. Porém, tensão e confusão mental não se alteraram.

Além disso, vale mencionar que estado de humor vigor, caracterizado como fator positivo, diminuiu após o primeiro jogo.

E que a depressão, a raiva e a fadiga, caracterizadas como fatores negativos, aumentaram após o primeiro jogo. Aliás, o estado de humor fadiga esteve alto ainda no início do segundo jogo.

Estes dados podem ter culminado na derrota no segundo jogo. Além disso, estes dados demonstram que por se tratarem de atletas amadores, são necessários muitos trabalhos físicos e psicológicos, e acredita-se que os jogadores não renderam tanto como deviam, pois se ganhassem apenas um jogo eles estariam classificados para a próxima fase e foi exatamente o que ocorreu.

Dessa maneira, entende-se como necessário a realização de outros estudos sobre as emoções e sentimentos dos jogadores de basquete, para que de algum modo possamos auxiliar em futuros campeonatos.

\section{REFERÊNCIAS}

ALMEIDA, M. B. de. Basquetebol: iniciação. 3. ed. Rio de Janeiro: Sprint, 2000.

BIAGGIO, A. M. B. Ansiedade, raiva e depressão na concepção de C. D. Spielberger. Revista de Psiquiatria Clínica, v. 25, n. 6, nov./dez. 1998.

BROTTO, F. O. Jogos cooperativos: O jogo e o esporte como exercício de convivência. Santos: Projeto Cooperação, 2001.

CRATTY, B. J. Psicologia no esporte. 2 ed. Rio de Janeiro: Prentice-Hall do Brasil, 1984.

FERREIRA, A. E. X. Basquetebol: técnicas e táticas: uma abordagem didática-pedagógica. São Paulo: EPU, 1987.

LAWTHER, J. P. Psicologia desportiva. Rio de Janeiro: Fórum, 1973. 
MONTI, F. de S. R. Ansiedade no piloto de automobilismo. (Monografia) - Educação Física, Universidade do Vale do Sapucaí, Pouso Alegre, 2006.

RUBIO, K. Psicologia do esporte. São Paulo: Casa do Psicólogo, 2000.

SAMULSKI, D. Psicologia do esporte. Barueri: Manole, 2002.

SILVA, A. C. Relação dos estados transitórios de humor e a desempenho em competição de handebol. 2006.

(Monografia) - Universidade do Vale do Sapucaí, Pouso Alegre, 2006. 


\section{Anderson Wagner dos Santos \\ Universidade do Vale do Sapucaí - UNIVÁS \\ Daniel Simões Rebello \\ Universidade do Vale do Sapucaí - UNIVÁS}

\section{Danielle Bernardes-Amorim}

Universidade do Vale do Sapucaí - UNIVÁS

\section{Referência do artigo:}

\section{ABNT}

SANTOS, A. W. et al. Estados transitorios de humor de atletas de basquete. Conexões, v. 6, p. 560-571, 2008.

\section{APA}

Santos, A. W., Rebello, D. S., \& Amorim, D. B. (2008) Estados transitorios de humor de atletas de basquete. Conexões, 6, 560-571.

\section{VANCOUVER}

Santos AW, Rebello DS, Amorim DB. Estados transitorios de humor de atletas de basquete. Conexões, 2008; 6: 560-571. 